\title{
Chapter 3 \\ Crowd Knowledge Sourcing - A Potential Methodology to Uncover Victims of Human Trafficking
}

\author{
Julia Muraszkiewicz
}

\section{Introduction}

Gary Marx wrote that 'Whether dealing with questions of justice, quality of life, security, health, the environment or other issues, the potential benefits of science and technology are hardly deniable'(Marx 2012). Yet, at the same time he is a profound champion of caution when it comes to technology. In 1985 Melvin Kranzberg, a historian of technology, delivered the address at the annual meeting of the Society for the History of Technology, in which he presented what is already known as Kranzberg's six laws of technology (Sacasas 2011). The first and most insightful one is that "Technology is neither good nor bad; nor is it neutral." Thus, the notion of technology always needs to be justified, controlled and should serve a purpose and not just be developed for the sake of it. This ethos forms the critical lens through which a recent use of technology by Europol is scrutinised in this article.

Today, technology provides opportunities to enable the participation of citizens and communities in policing at their chosen level (Longstaff et al. 2015, p.38). Simultaneously technology allows law enforcement agencies (LEAs) to better harness the knowledge possessed by communities and use local intelligence to address crimes. This is especially true of crimes that happen in the community, one such crime is the exploitation of persons e.g., through human trafficking. This can be achieved through the use of crowd knowledge sourcing solutions (defined below).

In July 2017, the BBC published an article detailing how Europe's police agency, Europol, has launched a webpage displaying images from instances of child sex abuse in an attempt to find the perpetrators and victims by asking members of society to report details that may point to intelligence. Europol's initiative provides a welcome opportunity to reflect on the opportunities brought about by technology in

\author{
J. Muraszkiewicz $(\bowtie)$ \\ Trilateral Research Ltd, London, UK \\ e-mail: julia.muraszkiewicz@trilateralresearch.com
}


the fight against a crime such as human trafficking. However, this author, even in her role as a promoter of the use of technology in addressing hidden and complex crimes, has to recognise the limits. The chapter thus aims to stand alongside others (Gerry et al. 2016) as part of an on-going and comprehensive debate on the role of technology in fighting human trafficking. It will be argued that whilst using crowd knowledge sourcing is an interesting method of harnessing aggregate knowledge amassed by society it is still a difficult and learning process, and may require better broadcasting.

\section{Crowd Knowledge Sourcing: Explained and Exemplified}

Crowd Sourcing is the utilization of the knowledge possessed by Web users for the collection and/or analysis of mass data (Howe 2006). Milo emphasizes that Wikipedia 'is probably the earliest and best known example of crowd-sourced data and an illustration of what can be achieved with a crowd-based data sourcing model'(Milo 2011). Crowd Knowledge Sourcing is conceptualized in this chapter as Crowd Sourcing that relies on harnessing people's knowledge. It is rooted in the reality that knowledge and data is embedded in society; we are a knowledge society.

One of the advantages of crowd sourcing is that anyone can contribute. Thus, those using it (in this case LEAs) have access to a wider knowledge pool. Crowd Knowledge Sourcing is enabled by the Internet and Web 2.0 technologies and 'In the Internet era, this has a great potential of generating information repositories that are otherwise very difficult to construct and for identifying new unforeseen solutions and products. The potential for cost-savings associated with crowd data sourcing also provides attractive procurement alternatives to companies bound to tight budgets, particularly during economic downturns' (Milo 2011).

The inherent characteristic of any crowd sourcing is that it relies entirely on participants making a voluntary contribution; in other words there is no contract, no salary and no obligation. Participants may decide which tasks to undertake, when and how much time they dedicate. Moreover, their work is not the product of market forces or any hierarchies (Wittke and Hanekop 2011, p.9), which undeniably means that participants 'are not subject to [...] instructions or assignment of tasks, nor are they under any obligation to perform or provide a particular service' (Wittke and Hanekop 2011, p.12).

Despite the fact that crowd sourcing relies on voluntary participation, large numbers of society members contribute; cases such as Wikipedia or open source software stand as proof. As concluded by Wittke and Hanekop (2011, p.12): 'voluntary contributions here are not on a small scale, nor sporadic or exceptional, but on a very large scale, systematic, and with lasting returns.' The key to success however is predominantly reliant on the task in question appealing to a large number of persons; whether because it is enjoyable, interesting, glorifying, gratifying or allows self-development and the establishment of a respectable online profile. Furthermore, 
von Hippel (2005, p.5) explains that persons will engage in crowd sourcing type activates if they result will benefit them directly. This can be justified by the references to rational choice theories. Importantly for this paper, this explanation for the success of crowd-sourced initiatives may cause an issue when we aim to rely on the community to fight human trafficking. This will be explained below, however in brief it is hypothesized that because the time and effort put in, is not toward one's own use or direct and obvious benefit, challenges as to efficiency will arise.

\section{Proposals to Use Crowd Knowledge Sourcing to Rescue Victims of Human Trafficking and Bring Perpetrators to Justice}

An array of factors contribute to the crime of human trafficking and it is widely accepted that the crime is related 'to different fields and interests: migration, organized crime, prostitution, human right, violence against women, the feminization of poverty, the gender division of the international labour market, unequal international economic relationships, etc' (Wijers and Van Doorninck 2005). To that list we can add technology, including the Internet. In particular, the Internet assists in sexual exploitation for it provides a space for traffickers and other exploiters to engage in illegal activities. Posting pictures of victims - whether to advertise their services or as part of online pornography - allows perpetrators to span across borders and reach unprecedented level of audiences. It also provides a cloak of invisibility; it is harder to find someone posting images from their bedroom then to spot a brothel in a city. This adds to trafficking as a prominent and complex security issue.

Tackling this phenomenon unsurprisingly requires new savvy resources; this is because the hidden and evolving nature of the crime mean that there is a natural limit to what law enforcements authorities will be able to do. As aptly highlighted by Couch (2016): '[h]uman trafficking cases can live or die based on how quickly detectives gather evidence. Several emerging technologies aim to speed up that process, including Traffic Jam, a software program launched in 2013 that combs through escort ads and uses machine learning to find patterns that can connect ads across multiple geographic locations to the same organization or pimp.' Technology thus provides LEAs with a new variation of gathering intelligence.

Detection of content that potentially concerns exploited persons is now common practice; 'software such as PhotoDNA can automatically detect illicit content' (Drewer and Ellermann 2016, p.200). The harder part can be determining where the victims who feature in the images or videos are being harboured and exploited. The police can take the content off line, but how, using the existing images, can they get access to the victims and help them? On balance the analysis of images - studying them and trying to uncover potential clues as to the whereabouts of the actors concerned - is an enormous task. This task can potentially be eased through the use of Crowd Knowledge Sourcing tools as recently demonstrated by Europol. In the 
on-going search for how to solve missing pieces of a crime puzzle and related to this, recognising their own limits, Europol launched a Crowd Knowledge Sourcing website: https://www.europol.europa.eu/stopchildabuse.

Criminals exploit human beings in a space that can be filled with clues as to their whereabouts. These clues are of course discrete, unrecognisable by most. However, in all likelihood there are persons in our society who will be able to identify a logo on a shopping bag in the corner of a room and connect it to a local shop. Or, they may spot packaging from a local takeaway and tell the Police which neighbourhood the exploitation has taken place.

The Europol site displays parts of images connected to child sex abuse, i.e. only showing one object. As summarised by Europol: 'The objects are all taken from the background of an image with sexually explicit material involving minors. For all images below, every other investigative avenue has already been examined. Therefore we are requesting your assistance in identifying the origin of some of these objects. We are convinced that more eyes will lead to more leads and will ultimately help to save these children.' The website showcases new approaches to how the police can access information with regards to cases of exploitation, which take place on the Internet. Whilst Europol is using the site for cases of sexual abuse concerning minors, the methodology can be extended to online cases of human trafficking.

An analysis of clues contained in images is potentially a good use of Crowd Knowledge Sourcing. In simplest terms it aims to rely on the public to help collect and figure out pieces of a crime jigsaw. To that end a number of images are uploaded, and 'each photo has an option underneath to send an anonymous tip to Europol or share on social media. The detectives want users to realise the potentially vital role they can play, they believe a few clicks could help to rescue a child' (BBC 2017). The Europol tool could potentially be a powerful mechanism by which communication on investigations is eased, moreover it can also have a significant impacts on public perceptions of the police: they are seen to be working hard at solving a heinous crime.

\section{Challenges of Using Crowd Knowledge Sourcing and Recommendations for the Way Forward}

Whilst the opportunities seem advantageous, questions arise about the likelihood of success and benefit. Building upon insights from Gary Marx we must acknowledge however that no matter how 'ideal a technical control system may appear in the abstract under ideal laboratory conditions or successful in the short run, the world of application is often much messier and more complicated than the public relations efforts claim' (Marx 2012). Marx understands that there is rarely a perfect technical solution, or one without issues. The same is true of a technical answer to community problems. 
In an attempt to challenge emerging technologies, scholars may first look to the privacy and ethical implications, particular when it comes to the domain of law enforcement technology. As highlighted by Finn et al. 'privacy is a key lens though which many new technologies, and most especially new surveillance technologies, are critiqued' (Finn et al. 2013, p.4). In the instance of the Europol platform however, it would seem that the identity of the victims and potential perpetrators is safeguarded through the method of removing any identifiable images. The removing of potentially sensitive data and anonymization of the images is a welcome step from the perspective of privacy law as well as ethics. Drewer and Ellermann (2016, p.197) writing about the European Counter Terrorism Centre highlight that 'the balance between privacy and security has always been central to law enforcement operations. Europol is proud to have implemented one of the most robust data protection regimes in the world of law enforcement. This allows the organisation to effectively support and strengthen Member States action in preventing and combating serious crime while duly respecting individuals' right for privacy.' There seems to be no deviation from this in using Crowd Knowledge Sourcing. The pictures show the bare minimum, and there are no personal sensitive data visible. Thus, the values around the human right to privacy, supposedly, remain intact.

Notwithstanding the above commendation for the Europol solution, it is suggested that our enthusiasm for the technology can be curbed by practical restrains; namely the requirement for an active, willing and diverse public. It is suggested that it is likely that interaction with a system like the one offered by Europol will be limited to those in the know of the system. Moreover, those in the know (e.g., relevant stakeholders working in this field) may not be the type of audience best matched for analysing the images. A successful identification relies on someone spotting a piece of local knowledge, and thus it requires the use of every day citizens across the relevant geographic space (e.g., the EU). To ensure accuracy and reliability law enforcement actors need to engage with the community at large. The likelihood, although the author found no available data as to the exact figures, is that the number of those in the know of the platform is relatively low compared to what would be required for wide-scale success. If society is not aware of the platform it logically follows that they will not use it. One recommendation that arises therefore is to better communicate the existence of the Crowd Knowledge Sourcing platform so as to ensure an inflow of participation from the general public. This, to a certain extent is being done as evidenced by the above-mentioned BBC article and also social media campaigns. However, ensuring the engagement of the community also requires support at not just neighbourhood levels but also at policy level; e.g., through the provision of funds to disseminate information about the various initiatives.

Related to the issue of ensuring a wide usage, is the question of motivation. What persuades large number of society members to regularly log on to the Europol system and examine the images? It is hypothesised that altruistic motivation would be the biggest factor, however this should be empirically researched. How much force does altruism carry? How can we increase the motivation? Myhill makes an in interesting point with regard to community policing more generally that can be transferred to the case of Europol's platform. 'Communities may not initially have the 
willingness to engage with the police, particularly in areas where there is a history of poor relations. This can sometimes be interpreted by officers as apathy. The police need to foster trust and confidence in these communities prior to attempting to secure community participation' (Myhill 2006, p.84). Thus what is needed is not only motivation, but also trust and confidence in the police and in their methods. This includes confidence that the platform is working. Myhill thus rightly highlights that 'the police must value the input and contribution of the public if partnerships are to be successful. Information flow must be two-way. The police need to provide communities with feedback on how their contribution is being used. If action is taken, this should be publicised. If action is not taken, the reasons for this should be explained' (Myhill 2006, p.85). Thus it is recommended that any initiative that seeks to rely on the society to help in solving crime puzzles also show cases the positive impact community involvement has had.

A further question arises, how can law enforcement authorities ensure that a momentum of motivation to voluntarily engage in this form of community participation is sustained? We can imagine that after seeing an advert about the Crowd Knowledge Sourcing site or reading about it on the news, individuals will log on. However, how do we make sure they regularly come back? Presumably much relates to socially embedding crowd knowledge sourcing in communities and again showing how their work is effective.

\section{Concluding Remarks}

This paper has reiterated the notion that human trafficking can be a hidden crime, difficult for law enforcement agencies to uncover and obtain evidence of. Yet the obligations on States stemming from international and regional legislation such as the 2011 EU Directive on Human Trafficking and policy requires due diligent crime investigation. Technological solutions are increasingly being proposed along with traditional approaches as a way to address crimes, including that of human trafficking and exploitation generally. Here there is potentially some room for Crowd Knowledge Sourcing as exemplified by Europol. Alongside introducing the technology this article sought to, through citing Gary Marx acknowledge that we should not blindly engage in a celebratory ethos of technology but approach it with scrutiny. We should question if it breaches the right to privacy and if it is in fact useful. As Marx says 'A police chief who says "if the technology is available, why not use it?" needs first to ask, "what are the likely consequences of using this technology, how does its use compare to that of other technologies and to the consequences of doing nothing?" (Marx 2003, p.25). It is argued by this author that the Europol online platform provides aggregate evidence gathering pathways, and opportunities to harness inherent knowledge held by the public that may otherwise not have reached the LEAs. It is a modus operandi that has been developed because all other 
options have been exhausted and the LEAs have reached a stalemate. However, to make the platform a successful instrument, we must address the important challenge of gathering crowd participation. The article recommends that two simultaneous approaches need to be undertaken. Firstly, there should be further research about what motivates persons to participate in community policing and how to ensure their engagement, specifically with regard to technology. Secondly, there should be greater efforts to communicate the existence of the tool, including from those at policy level. TV and radio ads are possible platforms. In addition, usage could be made of community clusters such as faith groups, which transcend socio-economic demographics.

\section{References}

BBC. (2017). Europol shows clues from child abuse images to track offenders. [Online] http:// www.bbc.co.uk/news/world-europe-40115549

Couch, C. (2016). How artificial intelligence can stop sex trafficking. PBS [Online] http://www. pbs.org/wgbh/nova/next/tech/sex-trafficking/

Drewer, D., \& Ellermann, J. (2016). May the (well-balanced) force be with us! The launch of the European Counter Terrorism Centre (ECTC). Computer Law \& Security Review: The International Journal of Technology Law and Practice, 32, 195-204.

Europol. (n.d.). Stop child abuse - Trace an object. [Online] https://www.europol.europa.eu/ stopchildabuse

Finn, R., Wright, D., \& Friedewald, M. (2013). Seven types of privacy. In S. Gutwirth, R. Leenes, \& P. De Hert (Eds.), European data protection: Coming of age? (pp. 3-32). Dordrecht: Springer.

Gerry, F., Muraszkiewicz, J., \& Vavoula, N. (2016). The role of technology in the fight against human trafficking: Reflections on privacy and data protection concerns. Computer Law and Security Review, 32(2), 205-217.

Howe, J. (2006). The rise of crowdsourcing. Wired Magazine - Issue 14.06, [Online] https://www. wired.com/2006/06/crowds/

Longstaff, A., Willer, J., Chapman, J., Czarnosmki, S., \& Graham, J. (2015). Neighbourhood policing: Past, present and future. The Police Foundation. [Online] http://www.police-foundation. org.uk/uploads/catalogerfiles/neighbourhood-policing-past-present-and-future---a-review-ofthe-literature/neighbourhood_policing_past_present_future.pdf

Marx, G. (2003). Some information age techno-fallacies. Journal of Contingencies and Crisis Management, 11(1), 25-31.

Marx, G. (2012). Technology and social control: The search for the illusive silver bullet continues. Encyclopedia of the Social \& Behavioral Sciences, 2nd edition, [Online] http://web.mit.edu/ gtmarx/www/techsoccon.html

Milo, T. (2011). Crowd-based data sourcing. In S. Kikuchi et al. (Eds.), 7th international workshop of databases in networked information systems. Heidelberg: Springer.

Myhill, A. (2006). Community engagement in policing Lessons from the literature. National Policing Improvement Agency. [Online] http://whatworks.college.police.uk/Research/ Documents/Community_engagement_lessons.pdf

Sacasas, M. (2011). Kranzberg's six laws of technology, a metaphor, and a story. [Online] https:// thefrailestthing.com/2011/08/25/kranzbergs-six-laws-of-technology-a-metaphor-and-a-story/

Von Hippel, E. (2005). Democratizing innovation. Cambridge: The MIT Press. 
Wijers, M., \& Van Doorninck, M. (2005). What's wrong with the anti-trafficking framework? Background Paper For The European Conference On Sex Work, Human Rights, Labour And Migration. ICRSE (International Committee On The Rights Of Sex Workers In Europe). [Online]. http://www.ide.go.jp/English/Publish/Download/Dp/pdf/289.pdf

Wittke, V., \& Hanekop, H. (2011). New forms of collaborative innovation and production on the internet. In V. Wittke \& H. Hanekop (Eds.), New forms of collaborative innovation and production on the internet. An interdisciplinary perspective (pp. 9-29). Universität Göttingen: Göttingen.

Open Access This chapter is licensed under the terms of the Creative Commons Attribution 4.0 International License (http://creativecommons.org/licenses/by/4.0/), which permits use, sharing, adaptation, distribution and reproduction in any medium or format, as long as you give appropriate credit to the original author(s) and the source, provide a link to the Creative Commons license and indicate if changes were made.

The images or other third party material in this chapter are included in the chapter's Creative Commons license, unless indicated otherwise in a credit line to the material. If material is not included in the chapter's Creative Commons license and your intended use is not permitted by statutory regulation or exceeds the permitted use, you will need to obtain permission directly from the copyright holder.

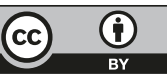

